\title{
Computer-Supported Collaborative Learning: Basic Concepts, Multiple Perspectives, and Emerging Trends
}

\author{
Sten R. Ludvigsen and Anders I. Mørch \\ InterMedia, University of Oslo, Norway
}

\begin{abstract}
Computer-Supported Collaborative Learning (CSCL) is the field concerned with how Information and Communication Technology (ICT) might support learning in groups (co-located and distributed). The chapter surveys key studies, common technologies, and significant events in the field. It presents basic concepts, multiple perspectives, and emerging trends in CSCL. A main distinction is drawn between the systemic and the dialogical approach to research. The former is rooted in the cognitive perspective on learning and the latter the sociocultural perspective on learning and development. Design-based research is prominent in the field and we differentiate pedagogical and technology design as two means to scaffold research, collaboration and learning.
\end{abstract}

Keywords: cognition, collaboration, computer supported collaborative learning (CSCL), design-based research, development, dialogic approach, empirical studies, feedback, information and communication technology (ICT), sociocultural perspective, systemic approach, technology design

\section{Introduction}

Computer-Supported Collaborative Learning (CSCL) is the field concerned with how Information and Communication Technology (ICT) might support learning in groups (colocated and distributed). It is also about understanding the actions and activities mediated by ICT. Educational applications range from generic collaboration environments (e.g. forums) to tools for developing domain-specific knowledge. The research questions addressed in CSCL include how individuals learn with specific tools, how small groups interact and develop shared meanings over time, how institutions change and create new conditions for teaching and learning, and even how the opportunities for learning change as society adopts new models for education. Societies increasingly require new types of knowledge, new means of knowledge advancement and, consequently, new models of education.

To account for the multiple perspectives associated with CSCL without risking oversimplification, we adopt a socio-cultural approach in order to present the main concepts and results. In particular, we make use of two overarching concepts scaffolding and mediating artifact. Scaffolding is an instructional technique whereby the teacher models the learning task, then gradually fades away and shifts responsibility to the students. In collaborative learning, students might also take on this role. By a technological scaffold, we mean features built into educational technologies that perform similar functions (e.g. guidance in virtual collaboration).

Related to scaffolding is the concept of mediation, proposed by Vygotsky (1986). This implies that technology for teaching and learning first of all is a mediating and enhancing artifact. A special type of mediation we explore in this chapter is the relation between design-based research and innovative CSCL tools (Collins, Joseph \& Bielaczyc, 
2004), on the one hand, and how this creates new opportunities for education on the other (Andriessen, Baker \& Suthers, 2003).

CSCL emerged in response to skills that are important in a knowledge-based society. These are skills that were previously associated with deep learning of specialized knowledge, meta-communication, meta-cognition, and task re-conceptualization (Järvela $\&$ Salovaara, 2004). These skills are not easily taught through memorizing and factfinding using textbooks, which are prevailing methods learning basic skills. In fact finding, for example, the goal of the activity is most often invisible to students and the focus tend to be on tasks (Hewitt, 2001).

The shift in perspective concerning learning and cognition that CSCL provides is, in part, a result of the raised expectations in a knowledge-based society. The labor market of today demands: 1) specialized (domain specific) skills and 2) an ability to work in teams (the capacity to integrate different types of knowledge and skills through collaboration). Specialized knowledge is important because the labor market is fragmented and interwoven in complex ways. The demands for skills in collaboration and knowledge integration (e.g. critically evaluate information resources found on the world wide web) have come to the foreground over the past 10 years, making the teaching of communication, information sharing and collaboration more important than ever.

CSCL is about teaching and learning the knowledge and skills required for participation in the knowledge-based society in concert with the basic skills they rely upon. The view we present in this chapter is consistent with those of scholars who argue that the needs for specialized knowledge and collaboration skills must be met with a comprehensive approach (Järvela \& Salovaara, 2004; de Jong 2006; Scardamalia \& Bereiter, 2006).

CSCL is also a result of the widespread use of web-based information systems and their acceptance by a broad group of actors at all levels in the education sector and by many workplaces (e.g. learning management systems, discussion forums). Two specific directions in educational research that have taken advantage of CSCL include ICT as mediators of accumulated knowledge (Paavola \& Hakkarainen, 2005) and ICT as cultural tools (Wertsch, 1991; Ludvigsen \& Mørch, 2003)

This chapter will cove the major issues, research approaches, and questions concerning CSCL We start by providing an overview of the field, including a presentation of key events and directions. Then we give an overview of some important results grouped into two research approaches. Next, we give an overview of design-based research and its implications for CSCL. In closing, we identify remaining open issues and point out some directions for further research.

\section{Background}

CSCL is a new and emerging field in the educational sciences (Stahl, Koschmann \& Suthers, 2006). The term was first publicly used at an international workshop in 1989 in Maratea, Italy. The first international conference was organized in 1995 (Koschmann, 1996), and since then a biannual series of CSCL conferences has been arranged across Europe, North America and Asia. In 2006, the International Journal of Computersupported Collaborative Learning (ijCSCL) had its inaugural issue.

Broadly speaking, there are two main traditions within the learning sciences: cognitive psychology and the situated/socio-cultural perspective. The former is based on 
the information processing perspective (e.g. Anderson, 1993) and the latter on American pragmatism (e.g. Dewey, Mead, Garfinkel, Schön,) and Soviet psychology (e.g. Vygotsky, Leontiev, Luria, Wertsch). In CSCL studies, methods and techniques from both traditions are used and sometimes blended (e.g. interaction analysis). However, within each tradition there are unique interpretation of key concepts, methods and empirical design.

Technical advances in computer science have contributed to CSCL in various ways. For example, researchers in Computer Supported Cooperative Work (CSCW) have developed groupware systems that have been adopted for educational purposes (e.g. Stahl, 2006). Groupware provide shared spaces (Bannon \& Bødker, 1997) on the WWW for storing and sharing information (messages, documents, pictures, videos) and engaging the learners in social interaction (Girgensohn \& Lee, 2002). When adopted in schools they allow teachers and learners to interact online using a variety of communication and collaboration tools. Examples of shared spaces are BSCL (Stahl, 2006), FLE (Muukkonen et al 1999), and Knowledge Forum (Scardamalia \& Bereiter, 2006).

The relationship between computer-support (CS) and collaborative learning (CL) in CSCL is complex as a result of the broad scope of the research questions, the multiplicity of approaches and the plethora of educational technologies. This complexity needs to be unraveled in order to provide a more comprehensive account of the field. Although technology has had an enormous influence on CSCL, educational technologies should not be thought of as recipes for how to organize teaching and learning. Similarly, the term "collaborative learning" does not imply that learning in small groups is better than individual learning. Findings indicate that detailed analyses of interaction are necessary to understand how collaboration is carried out (Arnseth \& Ludvigsen, 2006). In other words, it is not a question of an either/or situation, but rather how to identify specific situations that require mastery of new skills and design pedagogical and technological scaffolding for those situations. The common denominator is Vygotskian epistemology that social interaction precedes learning and cognition at the level of the individual. To design for this requires CSCL tools that foster social interaction and ease the transition from social interaction to learning and development. In this way, CSCL both represents a subfield in educational research and broadens the scope of educational research since it interacts with computer science and information systems.

\section{Research approaches in CSCL}

We have grouped mainstream CSCL research into systemic and dialogical approaches (Arnseth \& Ludvigsen, 2006). This distinction gives us the possibility to provide a more aggregated picture of what we know about research in CSCL.

\subsection{Systemic approach}

The systemic approach concerns the generation of models of how specific features of technological systems support or constrain collaboration, reasoning, knowledge representation, and structure of discourse (Dillenbourg, 1999) and to what extent these features will enhance students' capacities to solve problem in different domains (Arnseth \& Ludvigsen, 2006). From a systemic approach, the analytic purpose is to identify interdependencies between quantifiable variables. The unit of analysis is the individually acting and thinking agent, and two important cognitive processes are internalization 
(acquiring new or improving existing knowledge) and transfer (what is learned in one situation is applied to another similar situation). Models (often computer generated) of how individuals construct, store, retrieve and modify information serve as explanations of these phenomena (Anderson, 1993; Greeno, 2006).

Using a systemic approach in a traditional classroom setting in mathematics and reading, Lamon et al. (1996) demonstrated that students with CSCL tools performed better than students without such tools. The Jasper project (The Cognition and Technology Group at Vanderbilt, 1990) also reported similar results. The researchers in this large project studied the impact of educational technology on mathematics education in North America. They found that cooperative problem solving and discussion helped to engage the students in learning. In Europe, Fischer and colleagues have studied how different types of scripts and tasks impact students' collaborative learning activities (Fischer \& Mandl, 2005). Technological (computer supported) scripts were used to scaffold actions, and social scripts, such as role distribution, were used to organize turn taking. The authors found that scripts were useful for scaffolding learning and knowledge construction. However, these finding did not hold for all types of conditions (these conditions will be further discussed in the last section of this chapter).

One of the most influential approaches within the systemic approach is knowledge building developed by Scardamalia and Bereiter (2006). Knowledge building is a model for distributed collaborative learning that is based on how professional scientists work to solve problems. The authors developed CSCL tools to support knowledge building (CSILE, Knowledge Forum). The latest version includes a webbased shared space (WebCSILE). A further development of the Knowledge Forum is the Future Learning Environment (Muukkonen, Hakkarainen \& Lakkala, 1999).

The activities students engage in when doing knowledge building can be formulated as a scientific inquiry process, and many studies have been conducted using this approach (e.g. Hewitt, 2001). The phases of scientific inquiry include problem identification, proposing personal theories or hypotheses, experimentation, critical evaluation, data interpretation, scientific explanation, and summarizing. The studies in this area demonstrate that students who are engaged in knowledge building develop a deeper understanding of the domain under study. However, not all students benefit (Ludvigsen \& Mørch, 2003). This may be related to the approach used, since a shortcoming in many of the studies is the timeframe adopted, which may range from a few hours to a few days. A consequence of this brevity is that conversational data is analyzed without taking into account the historical context of the interaction, which unfolds over time. The implication of such an approach is that the students' learning trajectories becomes less visible in the analysis (Crook, 1998; Rasmussen, 2005). de Jong (2006) summarized recent research in scientific inquiry learning. He found that a number of students learn more effectively and develop deepening knowledge when supported with CSCL tools. The recommendation de Jong proposes is that it is possible to design scaffolding mechanisms into CSCL environments that enhance students' learning. On the other hand, the results also show that most students have problems using predefined structures and processes adopted from professional science. An explanation for this difficulty is that the students do not have sufficient background knowledge to grasp the significance of the scientific inquiry process, and prefer instead to use everyday interpretations of scientific phenomena. Using a professional model of 
science to scaffold a learning environment provides certain kind of insight, but it also generates new problems that are not easily explained with a systemic approach.

In summary, the systemic approach gives useful guidelines for how we can build scaffolds for cognitive processes like hypothesis generation, data interpretation, and scientific explanation. However, this model-based approach to learning and cognition needs to be supplemented by a situated approach from a social and cultural perspective to provide a full account of CSCL.

\subsection{Dialogic approach}

The dialogical approach is based on the idea that learning is a socially organized activity. The unit of analysis is a group of individuals interacting to accomplish a shared goal. Key concepts are mediation, artifacts and tools, and social practice, and mediation by tools to support learning is essential. It is through talk and interaction with significant others that we can understand how participants use tools and resources in learning and cognition. Externalization is seen as the main cognitive activity. The dialogic approach is influenced by research in situated learning and socio-cultural perspectives (Greeno, 2006; Vygotsky 1986; Rommetveit, 1992; Valsiner \& Van der Veer, 2000; Wertsch, 1991). A basic premise is that both physical and abstract tools mediate human activities, and the main abstract tool is language (Vygotsky, 1986). The use of tools for learning is not only goal driven, but can also be seen in connection with how tools connect us with the past (predecessor artifacts) and with the future (unexplored potentials). The tools span both spatial and temporal dimensions.

In a study performed by Mercer and Wegerif (1999), students were exposed to a set of ground rules for communication. These rules included the use of arguments, disputes, clarifications, and explanations. The students and teachers were trained to talk together in specific ways in order to develop shared knowledge about a specific phenomenon of interest. In a series of interventions, the ground rules became a focus of the inquiry and previously implicit structures, like norms for participation, became explicit and transparent. This increased the probability for a kind of talk Mercer and Wegerif (1999) refer to as exploratory talk. Exploratory talk is characterized by the mutual development of problems and ideas over time as a result of elaboration and reflection. They designed learning environments and new types of tasks to support these activities to promote more productive interactions in classrooms. It is further suggested that productive interaction needs to be understood not only as sequences of interaction, but as part of a broader context of institutional activities and socio-cultural developments (Crook, 1998; Arnseth \& Ludvigsen, 2006).

An example of a micro-study using the dialogic approach is the study of the effects of copy and paste on learning productivity. The cognitive effort involved in using copy and paste for text production and school presentations is low. As a result, many students use this technique uncritically. Some scholars have argued that it does not promote learning and should be discouraged (Hewitt, 2001; Kumpulainen \& Wray, 2002). Using the dialogic approach, we can study this phenomenon in conjunction with how participants use the tools they have at their disposal to identify how the talk among the participants unfold as result of tool mediation and emergent intermediate processes. Rasmussen (2005) found that students used copied texts as resources to deepen and broaden their understanding of the subject they studied. 
Another finding concerning the use of the dialogic approach is that tasks are often open-ended and cannot be taken for granted (Rasmussen, 2005). When studying how talk emerges in interaction as an analytic approach, the task needs to be constructed among the participants (Linell, 1998). The effect of this is that understanding the task becomes a learning activity in its own right, and this will stimulate the development of a higherorder skill (task conceptualization). When we assume students working together share goals, task re-conceptualization should be seen as an outcome of the activities rather than part of the premises for working together.

Suthers (2005) has identified intersubjective meaning making (Rommetveit, 1992) as one of the unique areas that CSCL is well equipped to support, and he suggest CSCL researchers undertake studies that attempt to understand how intersubjective meaning making impact learning and how it can be mediated by technology affordances (Norman, 1999) embedded in CSCL tools. Suthers (2005) defines intersubjective meaning making as joint composition of interpretations of a dynamically changing context. With this proposal he provides a bold attempt to go beyond an information sharing conception of collaborative learning. Technological affordances for exploratory learning and joint problem solving are proposed to support this process.

In summary, a dialogical approach to CSCL provides new analytic concepts to analyze how students and teachers interact in collaborative learning. The dialogic approach gives broader insights and explanations concerning the development of traditional skills, and pays particular attention to skills such as those for communication, coordination, information sharing, collaboration, negotiation, critiquing, and decisionmaking, and how to design CSCL tools to support these activities.

\section{Design-based research}

\subsection{Pedagogical design}

Design-based research (DBR) has influenced research methodology in CSCL. DBR provides a solution for one of the dilemmas that confront researchers in the field. On the one hand, understanding how people learn, particularly within school settings, and on the other designing ways to better ensure that learning will happen in these settings (Brown, 1992; Collins, Joseph \& Bielaczyc, 2004). The development of DBR has been on theoretical and methodological levels. On the methodology level DBR suggests partnerships among researchers and educators with the goals of conducting rigorous and reflective inquiry, testing and refining innovative learning environments, and defining new design principles based on previous research (Sandoval \& Bell, 2004). On the theoretical level design principles is the practical application of what we know about learning. As such, DBR does not provide direction for which research approach would be appropriate. Both the systemic and the dialogical approaches could be used.

\subsection{Technology design}

The link between DBR and technology design is harder to establish. This is a result of the focus on theoretical and methodological issues (not well integrated with technological issues) and the difficulty involved in creating design principles that are practically useful for technology developers. There is an implied link between design principles and technological affordances in that the latter propose solutions to the former. However, this 
is a normative assumption upheld by some CSCL researchers, arguably strongest in the systemic tradition. Although many educational researchers agree that the basic principles of the socio-cultural approach are important for the design of learning environments, the adoption of these principles have been hampered by a complex chain of elaborations before the principles can be used for developing specific tools. This is an important area for further work in CSCL (e.g. Suthers, 2005).

The basic idea of design principles in DBR is that we make use of what we know about previous research on learning when we design new learning environments. Although there is not an exact correspondence between the design principles proposed based on previous empirical studies and the design of an innovation for a new setting, the idea that the designers try to support the learning processes and anticipate its outcomes in specific directions is likely to succeed over time. For example, the principle of "deep learning" can be found in many CSCL-environments, in various forms (e.g. Linn, Bell \& Davis, 2004, Scardamalia \& Bereiter, 2006). de Jong (2006) provides a recent overview.

The integration of design principles with technological affordances works best for principles that lend themselves to tool support, such as scaffolding. This principle has successfully been incorporated into many CSCL tools, often in the form of automated feedback and/or guidance. Technological scaffolding of this sort takes advantage of regularities of:

- Subject domains (Fischer et al., 1991);

- Knowledge types and scientific inquiry (Muukkonen, Hakkarainen \& Lakkala, 1999; de Jong, 2006);

- Presence of others, group awareness, and social networks (Kreijns \& Kirschner, 2004);

- Feedback and advice for online collaboration (Soller et al., 2005; Mørch et al., 2005).

One debate among technology developers concerns the degree to which computerized feedback should simulate or provide higher-level representations of user interaction data before output (feedback, guidance) is generated. Soller and colleagues (2005) suggest three levels of feedback: mirroring (awareness), meta-cognitive tools and guidance. This gradually increases the system's interpretation of the user data and consequently requires the users to be equally critically aware of the feedback presented.

Another debate is to what extent automated feedback should be proactive, reactive or latent (Mørch et al., 2005). A system that provides sentence openers and step-by-step guidance is proactive. If it allows "wrong" actions to be taken before it gives hints and critique, it is reactive. If the system does not take any suggestive action on its own at all, but allows the learner to request guidance upon demand, it is latent (Mørch et al., 2005). All three intervention strategies are important in CSCL environments, but not at the same time. The equation for balancing the three strategies depends on the complexity of the knowledge domain to be supported (e.g. the severity of making a wrong move vs. stimulating explorative learning) and the choice of research approach (systemic vs. dialogic).

\section{Open issues and directions for further work}


In the 1990s, many people discussed how technology and the Internet would revolutionize schools and educational institutions. Now, after a ten-year period, these assumptions' seems rather opaque and romantic. The CSCL research has, to a large degree, provided insight concerning which condition we can expect students to develop deep knowledge using innovative technology support. A reasonable interpretation for the CSCL field across the different traditions we have surveyed in this chapter, emphasizes that such capacity needs to be cultivated over a number of years, and it is dependent on how the learning environments is designed, the social norms of the actors involved, and the institutional settings (Krange \& Ludvigsen, 2008).

Two of the more general tendencies in complex CSCL environments are, firstly, that teachers and students need to engage deeply in specific problem-solving activities in order to learn concepts that are part of their actual knowledge development. The second tendency is that such deep engagement often involves disagreement, identifying problems and conflicting ideas that needs to be resolved (problematizing), providing explanations, negotiations, etc. However, disagreement is not always a necessary condition. In exploratory talk, for example, reciprocal elaboration also serves as a means for engaging in deep learning. We need to conceptualize tensions, breakdowns, alignments, and elaborations as basic activities for learning to become productive for students over a long period of time.

Improving educational settings with the scaffolding techniques for collaborative learning is one of the aims of CSCL. This improvement includes pedagogical and technological support for problematizing tasks, hypothesis generation, elaboration, judgment about resources from the Internet, interpretation of data, evaluation of performance (meta-cognition), deliberate perspective shifts, etc. This is likely to be accomplished by scaffolding at the level of action and activities in classrooms, and supported by CSCL tools. The approaches developed by the CSCL community deal with micro-level phenomena and educational practices as seen from the teachers' and learners' points of view. In this way, CSCL has contributed to how schools can become better places for teaching and learning, and it is through the adoption and use of technology as a mediating artifact that it has achieved this status (Rasmussen, 2005; de Jong, 2006; Scardamalia \& Bereiter, 2006). The historical tensions between "old" and "new" social practices create grounds for further development. It is the cognitive, social, historical and institutional aspects, in combination, that must be taken into account in order for us to understand how we can improve the learning condition for students.

The systemic and the dialogical approaches to CSCL provide directions for how educational practices can and should be changed. However, an ongoing issue concerns how to constructively combine them. Carefully designed (e.g. model-based) CSCL environments are important for improving our understanding of learning with ICT-tools, but the analysis should be done from multiple perspectives, drawing on a broader set of student skills. Only by taking multiple perspectives as a starting point can we identify commonalities across approaches that enrich our understanding of social interaction, of learning and cognition, as well as how to design new learning environments that enhance both productive learning and cognitive performance.

\section{Acknowledgements}


We want to thank InterMedia, The University of Oslo and the Competence and Media Convergence $(\mathrm{CMC})$ program at the university for financing our work with this chapter. We thank Dr. Hans Christian Arnseth, Dr. Andreas Lund, and Dr. Ingvill Rasmussen for providing critical and constructive comments on a previous version of this chapter.

\section{References}

1. Anderson, J. R. (1993): Rules of Mind. Hillsdale, New Jersey: Lawrence Erlbaum.

2. Andriessen, J., Baker, M. \& Suthers, D. (Eds.) (2003). Arguing to Learn: Confronting Cognitions in Computer-Supported Collaborative Learning Environments. Dordrecht: Kluwer Academic Publishers.

3. Arnseth, H.C. \& Ludvigsen, S. (2006). Approaching institutional contexts: Systemic versus dialogical research in CSCL. International Journal of ComputerSupported Collaborative Learning. 1, 2, 167-185.

4. Bannon, L. and Bødker, S. (1997). Constructing Common Information Spaces. Proceedings of the European Conference on Computer Supported Cooperative Work (ECSCW'97). Dordrecht: Kluwer Academic Publishers, pp. 81-96.

5. Brown, A. L. (1992). Design experiments: Theoretical and methodological challenges in creating complex interventions in classroom settings. The Journal of the Learning Sciences, 2(2), 141-178.

6. Brown, J.S. (2000). The Social Life of Information. Boston: Harvard Business School Press.

7. The Cognition and Technology Group at Vanderbilt (1990): Anchored Instruction and Its Relationship to Situated Cognition. Educational Researcher, Vol. 19, Nr. 6, pp. 2-10.

8. Collins, A., Joseph, D., \& Bielaczyc, K. (2004). Design research: theoretical and methodological issues. The Journal of the Learning Sciences, 13(1),15-42.

9. Crook, C. (1998). Children as Computer Users: The Case of Collaborative Learning. Computers \& Education, 30 (3 \& 4), 237-247.

10. de Jong, T. (2006). Scaffolds for Scientific Discovery Learning. In J. Elen \& D. Clark (Eds.), Handling complexity in learning environments: research and theory (pp. 107-128). London : Elsevier Science Publishers

11. Dillenbourg, P. (Ed.) (1999). Collaborative Learning: Cognitive and Computational Approaches. Amsterdam: Pergamon Press. 
12. Fischer, G., Lemke, A. C., Mastaglio, T., and Morch, A (1991). The role of critiquing in cooperative problem solving. ACM Transactions on Information Systems, 9(2), 123-151.

13. Fischer, F., \& Mandl, H. (2005). Knowledge convergence in computer-supported collaborative learning: The role of external representation tools. Journal of the Learning Sciences, 14 (3), 405-441.

14. Girgensohn, A. and Lee, A. 2002). Making Web Sites be Places for Social Interaction, Proc. ACM 2002 Conf. Computer Supported Cooperative Work, ACM Press, 2002, pp. 136-145.

15. Greeno, J.G. (2006). Learning in Activity. In Sawyer, R.K. (Ed.) The Cambridge Handbook of The Learning Science. Cambridge, Cambridge University Press.

16. Hewitt, J. (2001). From Focus on Tasks to a Focus on Understanding: The Cultural Transformation of a Toronto Classroom. In T. Koschmann, R. Hall \& N. Miyake (Eds.), CSCL 2. Carrying Forward the Conversation. Mahwah, NJ: Lawrence Erlbaum.

17. Järvelä, S. \& Salovaara, H. (2004). The interplay of motivational goals and cognitive strategies in a new pedagogical culture. A context oriented and qualitative approach. European Psychologist, 9, 4, 232-244.

18. Kreijns, K and Kirschner, P.A. (2004). Designing sociable CSCL environments. In J. W. Strijbos, P.A. Kirschner, \& R.L. Martens (Eds.), What we know about CSCL: And implementing it in higher education. Boston: Kluwer Academic/Springer Verlag, pp. 3-31.

19. Krange, I. and Ludvigsen, S. (2008). What does it mean? Students' procedural and conceptual problem solving in CSCL environment designed within the field of science education. International Journal of Computer supported collaborative learning, 3, 25-51.

20. Kumpulainen, K., \& Wray, D. (Eds.). (2002). Classroom Interaction and Social Learning. From Theory to Practice. London: Routledge/Falmer.

21. Lamon, M., Secules, T., Petrosino, A., Hackett, R., Bransford, J., \& Goldman, S. (1996). Schools for thought: Overview of the project and lessons learned from one of the sites. In L. Schauble, \& R. Glaser (Eds.), Innovations in learning: New environments for education. Mahwah, NJ: Lawrence Erlbaum.

22. Linell, P. (1998): Approaching dialogue: Talk, interaction and contexts in dialogical perspectives. Amsterdam: John Benjamins Publishing Company.

23. Linn, M. C., Bell, P., \& Davis, E. A. (2004). Specific design principles: 
Elaborating the scaffolded knowledge integration framework. In M. Linn, E. A. Davis \& P. Bell (Eds.), Internet environments for science education (pp. 315341). Mahwah, NJ: Lawrence Erlbaum Associates.

24. Ludvigsen, S. R. \& Mørch, A. (2003). Categorisation in knowledge building: Task specific argumentation in a co-located CSCL environment. In B. Wasson, S. Ludvigsen \& U. Hoppe (Eds.), Designing for Change in Networked Learning Environments. Proceedings of the International Conference on Computer Support for Collaborative Learning. Dordrecht: Kluwer Academic Publishers, pp. 67-76 .

25. Mercer, N. \& Wegerif, R. (1999). Is 'exploratory talk' productive talk? In K. Littleton \& P. Light (Eds.), Learning with Computers. Analysing productive interaction. London: Routledge.

26. Muukkonen, H., Hakkarainen, K., \& Lakkala, M. (1999): Collaborative technology for facilitating progressive inquiry: Future learning environment tools. In C. Hoadley \& J. Roschelle (Eds.) Proceedings for: Computer support for collaborative learning. Designing new media for a new millennium: Collaborative technology for learning (pp.406-415). Stanford University, CA: Lawrence Erlbaum Associates.

27. Mørch, A., Jondahl, S., Dolonen, J. (2005). Supporting Conceptual Awareness with Pedagogical Agents, Information Systems Frontiers, special issue on Computer Supported Collaborative Learning Requiring Immersive Presence, 7(1), pp. 39-53.

28. Paavola, S., and Hakkarainen, K. (2005). The knowledge creation metaphor: An emergent epistemological approach to learning. Science \& Education, 14, 537557.

29. Rasmussen, I. (2005). Project work and ICT: A study of learning as trajectories of participation. PhD thesis. InterMedia, University of Oslo, Norway.

30. Rommetveit, R. (1992): Outlines of a dialogically based social-cognitive approach to human cognition and communication. In Wold, A.H. (red.) The Dialogical Alternative: Towards a Theory of Language and Mind (s. 19-44). Oslo: Scandinavian University Press.

31. Sandoval, William A. \& Philip Bell (2004), Design-Based Research Methods for Studying Learning in Context: Introduction, Educational Psychologist, Vol. 39, No. 4: pages 199-201.

32. Scardamalia, M. \& Bereiter, C. (2006). Knowledge Building: Theory, Pedagogy, and Technology. In Sawyer, R.K. (Ed.). The Cambridge Handbook of The Learning Science. Cambridge, Cambridge University Press. 
33. Soller, A., Martinez, A., Jermann, P. and Muehlenbrock, M. (2005). From Mirroring to Guiding: A Review of State of the Art Technology for Supporting Collaborative Learning. International Journal of Artificial Intelligence in Education, vol. 15, pp. 261-290.

34. Stahl, G. (2006). Group cognition: Computer support for building collaborative knowledge. Cambridge, MA: MIT Press.

35. Stahl, G. , Koschmann, T., \& Suthers, D. (2006). Computer-Supported Collaborative Learning. In Sawyer, R.K. (Ed.) The Cambridge Handbook of The Learning Science. Cambridge, Cambridge University Press.

36. Suthers, D.D. (2005). Technology affordances for intersubjective learning: A thematic agenda for CSCL. In T. Koschmann, D. Suthers \& T. W. Chan (Eds.). Proceedings of Conference on Computer Supported Collaborative Learning 2005. Mahwah, NJ: Lawrence Erlbaum Associates. pp. 662-671.

37. Valsiner, J. \& Van Der Veer, R. (2000). The Social Mind: Construction of the Idea. Cambrigde, MA: Cambrigde University Press.

38. Vygotsky, L. (1986). Thought and Language. Cambridge MA: The MIT Press.

39. Wertsch, J. V. (1991): Voices of the mind. A sociocultural approach to mediated action. Cambridge, MA.: Harvard University Press. 


\section{Author Biography}

Sten R. Ludvigsen is professor and director at InterMedia, University of Oslo, Norway. $\mathrm{He}$ received his $\mathrm{PhD}$ in educational sciences (education psychology) from the University of Oslo based on a study of learning in medical institutions. His research interests include how to use digital learning resources in education, the relationship between co-located and distributed settings, and boundary crossing between education and workplaces. Ludvigsen leads the new Ph.D. program in learning, communication and ICT at the Faculty of Education, University of Oslo, and the Norwegian national research school in educational sciences (NATED), funded by the Research Council of Norway from 2008 to 2016. He has published more than 65 articles, papers and book chapters. Contact him at sten.ludvigsen@intermedia.uio.no.

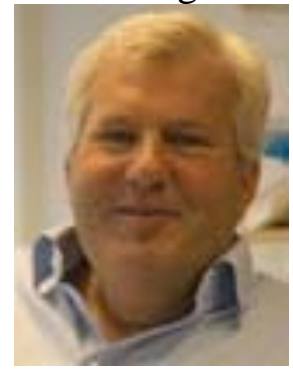

Anders I. Mørch is associate professor at InterMedia, University of Oslo, Norway. He is coordinator of the research unit ICT and Learning at Work. He received his $\mathrm{PhD}$ in informatics from the University of Oslo, and an M.S. in computer science from the University of Colorado, Boulder. He has developed educational technology at the NYNEX Science and Technology Center, New York. His research interests include computer-supported cooperative work, computer-supported collaborative learning, educational applications of software agents, and theory-informed interaction design. Mørch has been involved in a number of European projects and international activities in the areas of technology-enhanced learning (TEL) and end-user development (EUD). Contact him at anders.morch@intermedia.uio.no.

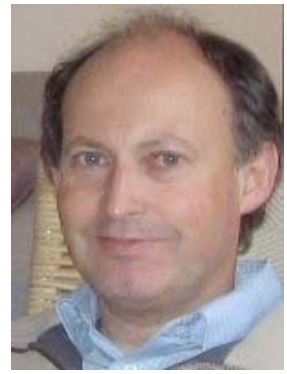

